\title{
Functional Organization and Dynamic Activity in the Superior Colliculus of the Echolocating Bat, Eptesicus fuscus
}

\author{
Melville J. Wohlgemuth, Ninad B. Kothari, and @Cynthia F. Moss \\ Department of Psychological and Brain Sciences, Johns Hopkins University, Baltimore, Maryland 21218
}

Sensory-guided behaviors require the transformation of sensory information into task-specific motor commands. Prior research on sensorimotor integration has emphasized visuomotor processes in the context of simplified orienting movements in controlled laboratory tasks rather than an animal's more complete, natural behavioral repertoire. Here, we conducted a series of neural recording experiments in the midbrain superior colliculus (SC) of echolocating bats engaged in a sonar target-tracking task that invoked dynamic active sensing behaviors. We hypothesized that SC activity in freely behaving animals would reveal dynamic shifts in neural firing patterns within and across sensory, sensorimotor, and premotor layers. We recorded neural activity in the SC of freely echolocating bats (three females and one male) and replicated the general trends reported in other species with sensory responses in the dorsal divisions and premotor activity in ventral divisions of the SC. However, within this coarse functional organization, we discovered that sensory and motor neurons are comingled within layers throughout the volume of the bat SC. In addition, as the bat increased pulse rate adaptively to increase resolution of the target location with closing distance, the activity of sensory and vocal premotor neurons changed such that auditory response times decreased, and vocal premotor lead times shortened. This finding demonstrates that SC activity can be modified dynamically in concert with adaptive behaviors and suggests that an integrated functional organization within SC laminae supports rapid and local integration of sensory and motor signals for natural, adaptive behaviors.

Key words: adaptive behavior; echolocation; natural vocalizations; neuroethology; sensorimotor; superior colliculus

Significance Statement

Natural sensory-guided behaviors involve the rapid integration of information from the environment to direct flexible motor actions. The vast majority of research on sensorimotor integration has used artificial stimuli and simplified behaviors, leaving open questions about nervous system function in the context of natural tasks. Our work investigated mechanisms of dynamic sensorimotor feedback control by analyzing patterns of neural activity in the midbrain superior colliculus (SC) of an echolocating bat tracking and intercepting moving prey. Recordings revealed that sensory and motor neurons comingle within laminae of the SC to support rapid sensorimotor integration. Further, we discovered that neural activity in the bat SC changes with dynamic adaptations in the animal's echolocation behavior.

\section{Introduction}

As animals operate in the natural world, sensory information guides behaviors on both short and long time-scales. Sensori- motor integration supports a variety of goal-directed actions, including saccades to a visual target (Wurtz and Goldberg, 1971; McIlwain et al., 1991) or reaching for an object (Werner et al., 1997; Stuphorn et al., 1999, 2000), as well as more complex sequences of adaptive behaviors such as tracking and intercepting prey (Furigo et al., 2010; Moss and Surlykke, 2010; Wagner et al., 2013) and avoiding predators (Brandão et al., 1994; Fanselow, 1994; Kavaliers and Choleris, 2001; Comoli et al., 2012; Maior et al., 2012). To investigate the neural underpinnings of sensorimotor integration in a dynamic and natural behavioral context, we

Correspondence should be addressed to Melville J. Wohlgemuth, Department of Psychological and Brain Sciences, Johns Hopkins University, Ames Building, 3400 N. Charles St., Baltimore, MD 21218. E-mail: melville.wohlgemuth@jhu.edu.

https://doi.org/10.1523/JNEUROSCI.1775-17.2017

Copyright $\odot 2018$ the authors $\quad 0270-6474 / 18 / 380245-12 \$ 15.00 / 0$ 
recorded neural activity chronically in the superior colliculus (SC) of an echolocating bat engaged in a sonar target-tracking task.

A wealth of data suggests that the midbrain SC plays an important role in sensorimotor integration. Across species, the functional organization of the SC reflects the importance of a particular sensory modality to an animal's natural behaviors. Early work stressed the representation of retinotopic visual space for eye movements as a model for collicular function (Schiller and Koerner, 1971; Cynader and Berman, 1972; Goldberg and Wurtz, 1972). Comparative data have documented the role of the SC in the saccadic eye movement system of primates (Sparks, 1986), in gaze-control orientation behaviors in cats and barn owls (Knudsen, 1982; Middlebrooks and Knudsen, 1984; du Lac and Knudsen, 1990; Munoz et al., 1991a), and in prey capture behaviors in pit vipers and frogs (Hartline et al., 1978; Grobstein, 1988). Neurophysiological studies of the primate and bat midbrain SC implicate this structure in auditory localization (Jay and Sparks, 1987; Valentine and Moss, 1997; Lee and Groh, 2012). Additional work in the bat has demonstrated premotor commands for sonar vocalizations, head movements, and adjustments of the pinnae (Valentine et al., 2002; Sinha and Moss, 2007) that are consistent with the notion that the SC supports species-specific orienting behaviors.

Biological sonar operates through tight coupling between sensing and action. Bats produce sounds that return echoes from objects in the environment, yielding acoustic cues for 3D localization (Griffin, 1958) The bat computes target azimuth from spectrotemporal differences of echoes at the two ears, elevation from echo spectrum, and distance from the time delay between sonar call and echo arrival (for review, see Wohlgemuth et al., 2016a). The spatial information that a bat extracts from echo features, then drives adaptive adjustments in vocal parameters, and changes in sonar vocalizations influence echo features available to the bat's sonar imaging system (Moss and Surlykke, 2010). The millisecond temporal precision of sensory and motor events for echolocation, coupled with the bat's adaptive sonar behaviors, provides a powerful system with which to investigate sensorimotor signaling in natural tasks.

In broad strokes, the canonical SC functional organization shows that neurons in dorsal layers respond largely to visual stimuli (Cynader and Berman, 1972; McIlwain, 1983; Berson and Stein, 1995), whereas intermediate layers show unimodal and multimodal sensory responses, and sensorimotor activity (May, 2006). In the more ventral layers, neurons are active before orienting movements of the body (Wurtz and Goldberg, 1971; Roucoux and Crommelinck, 1976; Ma et al., 1990; Peck, 1990). These results were primarily identified in visually guided primates and cats, and comparative studies in other species have reported more mixing of sensory and motor neurons across the dorsal-ventral axis of the SC (May, 2006). Does this organizational plan also hold for animals that rely largely on hearing to guide natural behaviors? How do natural adaptive motor behaviors influence sensorimotor signaling? We hypothesize that dynamic orienting, in which an animal must execute a complex sequence of sensorimotor behaviors (e.g., target tracking and interception), reveals a more integrated functional organization within and across laminae of the SC, in which local pools of neurons facilitate rapid sensorimotor integration.

Here, we exploited bat sonar orientation to characterize auditory and vocal premotor activity across the SC laminae in animals actively engaged in dynamic sensorimotor behaviors for prey tracking and interception. We discovered that activity patterns of sensory and vocal premotor neurons in the SC were modulated by the natural echolocation behaviors of the bat. Furthermore, both sensory and vocal premotor neurons could be characterized throughout all SC layers, providing evidence for an integrated functional organization, which supports rapid sensorimotor signaling for adaptive orienting behaviors.

\section{Materials and Methods}

Animals and behavioral training. Four wild-caught big brown bats (Eptesicus fuscus, three females and one male) served as subjects in this study. The bats were collected in the state of Maryland under a permit issued by the Department of Natural Resources and were housed in animal vivaria at the University of Maryland-College Park and Johns Hopkins University. All procedures used were approved by the Institutional Animal Care and Use Committees at the University of Maryland and Johns Hopkins University, where this research was conducted.

The behavioral paradigm in the current experiment was described in detail in a previous report (Wohlgemuth et al., 2016b). Briefly, the bats were initially trained to associate a sound stimulus with the presentation of a food reward (mealworms). Once this contingency was acquired, the presentation of the food reward gradually involved greater distances traveled by the target until the bats learned to track the target from a distance of $4 \mathrm{~m}$. The target's motion was controlled via a computer that interfaced with a rotary servo-motor (Aerotech Ensemble MP10 motor controller connected to a BMS60 servo motor). A loop of monofilament line was suspended on a set of four pulleys and wound around the rotary motor (Fig. 1A). A bundle of mealworms was then tethered to the monofilament line and, by driving the rotary motor, the velocity, acceleration, and direction of target travel were controlled experimentally.

The lighting in the room prevented the bats from using vision so that they instead had to rely on sonar to track the movement of the target (Hope and Bhatnagar, 1979). The target moved along the range axis, with no change in azimuth or elevation (see Fig. $1 B$, top, for example target motion and example vocalizations). The bats made adaptive modifications to their sonar vocalizations that were typical of a free-flying bat tracking a target closing in distance (Moss and Surlykke, 2010; Kothari et al., 2014; Wohlgemuth et al., 2016a), demonstrating decreases in pulse interval and pulse duration with decreasing target distance (Fig. 1C).

Surgical methods and physiological recordings. Once the bats learned the behavioral task, a 16-channel silicon probe affixed to a microdrive was chronically implanted into the SC. The silicon probe had 4 shanks with a $4 \times 4$ grid of recording sites. Recording sites were separated by $100 \mu \mathrm{m}$ on each shank and $100 \mu \mathrm{m}$ between shanks. The microdrive was advanced manually through the layers of the SC during the experiment at $25 \mu \mathrm{m}$ intervals, allowing us to finely sample SC activity at different locations along the dorsal-ventral axis. Data were collected from the SC of the four bats at 56 unique recording locations. With 16 available sites and 56 different recording locations, there were 896 unique recording locations sampled (i.e., $56 \times 16=896$ ), but not every site yielded neural activity. Neural data were collected with a Plexon Omniplex acquisition system; recordings of the bat's sonar vocalizations were made with a National Instruments $\mathrm{M}$-series $\mathrm{A} / \mathrm{D}$ board. The target motion was controlled using custom MATLAB (The MathWorks) software routines that additionally generated a TTL pulse for time synchrony across hardware systems.

Histological verification of recording sites. At the conclusion of each experiment, the bats were perfused with $4 \%$ paraformaldehyde. The brains were then removed from the skull and submerged in a solution of $4 \%$ paraformaldehyde with $30 \%$ sucrose for cryoprotection. Once the brains were cryoprotected, they were embedded in Optimal cutting temperature compound, frozen, and $50 \mu \mathrm{m}$ coronal sections were cut on a cryostat. The sections were then mounted on slides and stained with cresyl violet to image the location of the silicon probe tracts. Delineation of the SC layers was confirmed by cross-referencing with previous histological reconstructions of the midbrain (Covey et al., 1987; May, 2006; Big Brown Bat Stereotaxis Brain Atlas, courtesy of E. Covey, University of Washington).

Experimental design and statistical analysis. In the four bats, neural activity was sampled from multiple locations along the dorsal-ventral 

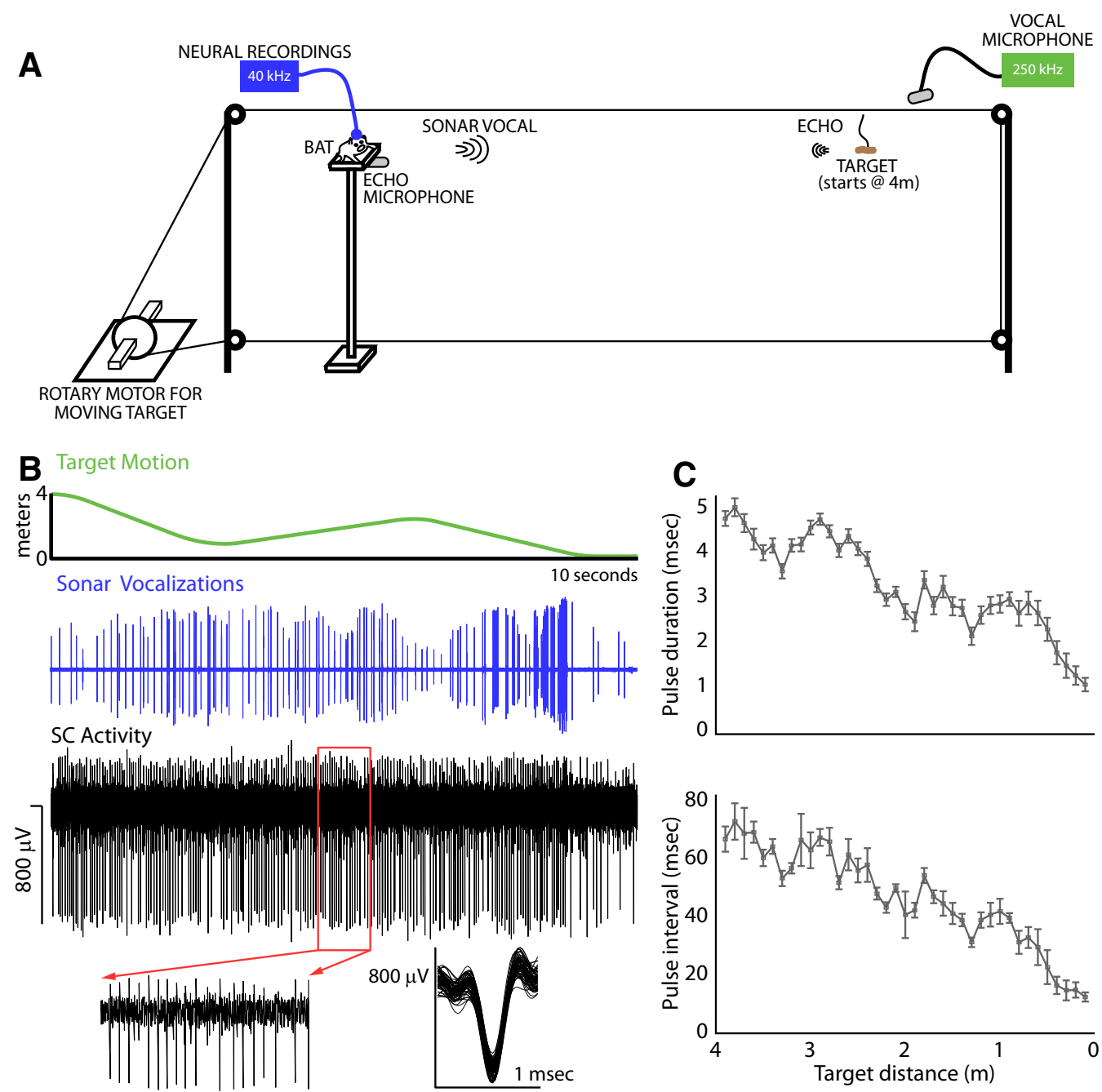

Figure 1. Experimental setup. $A$, Bat is trained to track a moving prey item from a stationary position. The prey item is suspended from a loop of monofilament wire that is connected to a rotary stepper motor that drives the wire around a set of four pulleys. The movement of the target can be controlled experimentally. While the bat tracks the moving target, ultrasonic microphones record sonar vocalizations and echoes, motion capture cameras record movements of the bat, and a 16-channel silicon probe records from the SC. $\boldsymbol{B}$, Top, Movement of the target for one trial in which the target travels back and forth in front of the bat before eventually arriving at the animal. Middle, Oscillogram of vocalizations produced by the bat while tracking the moving target. Bottom, Raw neural recording (band-pass $600-3000 \mathrm{~Hz}$ ) in the $\mathrm{SC}$ from a bat that was tracking the moving target. Bottom, Larger view of the highlighted region neural trace (left) and 100 randomly selected spikes showing spike consistency (right). C, Top, Sonar pulse duration as a function of target distance. Bottom, Sonar pulse interval as a function of target distance. Distances are binned into $10 \mathrm{~cm}$ bins.

axis (Bat A, 21 recording locations; Bat $\mathrm{B}, 18$ recording locations; Bat $\mathrm{C}$, 11 recording locations; and $\mathrm{Bat} \mathrm{D}$, six recording locations). While chronic recordings were taken in the SC (digitized at $40 \mathrm{kHz}$ ), the bat's sonar vocalizations were recorded with an ultrasonic microphone sampled at $250 \mathrm{kHz}$ and the position of the target was sampled at $1 \mathrm{kHz}$.

Once neural and behavioral data were collected, analysis was performed to relate the animal's adaptive sonar call production and echo reception to changes in the activity of SC neurons. First, the wideband neural traces were filtered between 600 and $3000 \mathrm{~Hz}$ to identify and sort action potentials from single neurons. This was performed through a wavelet-based clustering algorithm (Quiroga et al., 2004). The clustering was run on each channel from the silicon probe (i.e., across 16 channels), identifying 268 neurons for Bat A, 176 neurons for Bat B, 51 neurons for $B$ at $C$, and 31 neurons for Bat D, totaling 526 neurons. A concurrent step in the analysis quantified the bat's echolocation behavior in the target tracking task. Recordings of the bat's vocalizations were analyzed to identify the onsets and offsets of each sonar pulse, corrected for the distance the microphone was placed in front of the bat. Across all recording sessions, there were between 15 and 54 target-tracking trials for each of the bats, totaling 34-1662 individual sonar vocalizations per recording session.
Once the onsets of sonar vocalizations were identified, time-aligned windows of SC activity were extracted from the recorded neural data for all neurons held for at least 100 vocalizations. We then determined whether SC activity increased around the time of sonar vocalizations by first measuring the baseline firing rate for each neuron when the bat was not actively tracking the target (i.e., during the intertrial periods). The neural activity was summed across $2 \mathrm{~ms}$ bins for this analysis. Our definition of an increase in neural activity was a firing rate $>3$ SDs above the baseline firing rate for at least $10 \mathrm{~ms}$. This criterion was based upon past studies of SC activity in the bat in which a threshold of 2 SDs above baseline firing rates was used (Sinha and Moss, 2007). We chose 3 SDs to be more conservative in our determination of reliable increases in SC activity. Of the 526 total neurons recorded, 242 showed an increase in firing rate $>3$ SDs above the mean baseline firing rate in a window starting $50 \mathrm{~ms}$ before sonar vocal onset and extending until $50 \mathrm{~ms}$ after sonar vocal onset. We then determined when the SC activity peaked with respect to sonar vocal onset. If the peak occurred before sonar vocal onset, then the neuron was classified as vocal premotor; if the peak in activity occurred after sonar vocal onset, then the neuron was classified as sensory (auditory); and if there were peaks before and after sonar vocal onset, then the neuron was classified as sensorimotor (Fig. 2). 

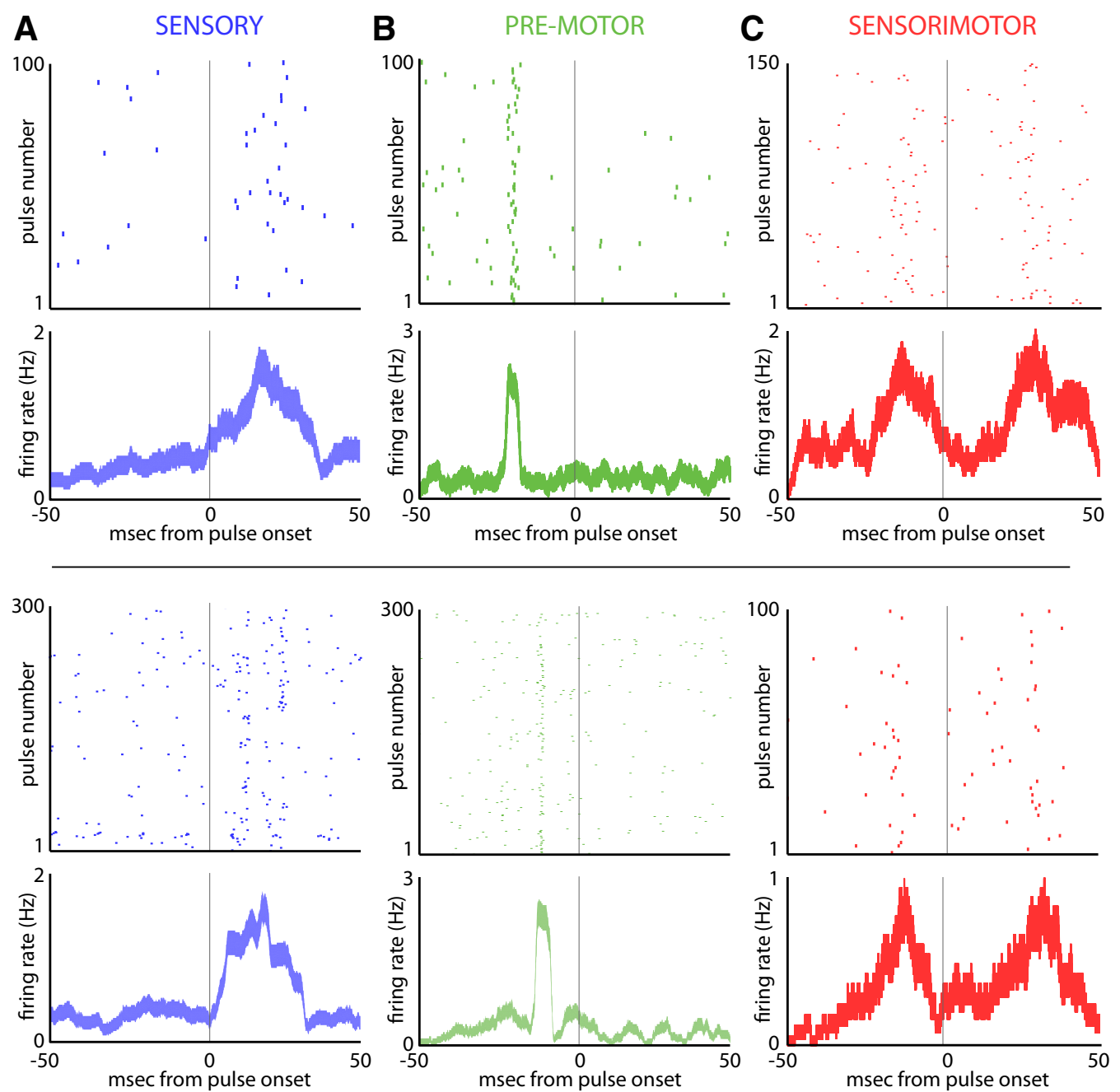

Figure 2. Sensory and motor activity in the SC. $A$, Top, Raster and firing rate plot of activity if a single SC neuron demonstrating a sensory or auditory response. For both the raster plot and peristimulus time histogram, activity is aligned to the onset of sonar vocalizations at zero. Tick marks in the raster plot show the time of spiking with respect to vocal onset, with 100 unique vocalizations stacked vertically. For this neuron, activity occurs after sonar vocal onset when the echo arrives and is therefore an auditory responsive neuron. The firing rate plot displays the mean \pm $\mathrm{SE}$ of the firing rate of the neuron, also aligned to sonar vocal onset. Bottom, Example of another SC neuron with a sensory response to echo arrival. $\boldsymbol{B}$, Top, Raster and firing rate plot for an SC neuron that is active before sonar vocal onset (the zero time point). This neuron is active $\sim 20 \mathrm{~ms}$ before vocal onset and is therefore categorized as premotor. Bottom, Another example of a neuron with an increase in activity before sonar vocal onset. C, Top, Raster plot and firing rate plot of a neuron with both vocal premotor activity and a sensory response after sonar vocal onset. This neuron is therefore classified as sensorimotor. Bottom, Another example of a sensorimotor neuron.

After each active neuron was classified as sensory, sensorimotor, or vocal premotor, we determined the corresponding depth of recording site. We then constructed histograms of the range of depths for each class of neuron and ran a two-tailed $t$ test to determine whether the average recording depths of sensory, sensorimotor, and vocal premotor neurons were significantly different. Next, to more closely analyze the relationship between the depth of a recording site and the timing of neural activity with respect to sonar vocalizations/echoes, we converted spike raster plots into heat maps, the color of which indicates the firing rate of the neuron. This was performed by determining instantaneous firing rates over $2 \mathrm{~ms}$ bins for SC activity occurring in a $100 \mathrm{~ms}$ window centered at sonar vocal onset. This firing rate was then mapped onto a color scale in which blue indicated the lowest firing rate and gold indicated the highest firing rate. Heat maps for each neuron (within a bat) were then arranged in order of increasing recording depth to examine changes in sensory and vocal premotor activity as a function of the dorsal-ventral position of the recording.

Next, we combined data from recorded neurons across bats to provide a more comprehensive analysis of changes in sensory and vocal premotor activity across the dorsal-ventral axis of the SC. To summarize these data in a figure, we first determined the spiking probability in $2 \mathrm{~ms}$ bins across a $100 \mathrm{~ms}$ window centered at sonar vocal onset. Spike probability was used for this analysis instead of spike rate to provide a normalized measure of activity across neurons. The spike probabilities of all 242 neurons were then arranged in order of increasing recording depth. Because there was some overlap in the recording depths across bats, we binned the range of recording depths (from $0-1200 \mu \mathrm{m}$ ) into $25 \mu \mathrm{m}$ bins and averaged the activity of neurons within each bin. This analysis resulted in a matrix of data in which the $X$-dimension represented the time axis and the $Y$-dimension represented the recording depth for all neurons. These data were then smoothed with a 2D Gaussian. The $X$-dimension of the Gaussian was $5 \mathrm{~ms}$ in width with a $2 \mathrm{~ms} \mathrm{SD}$. The $Y$-dimension of the Gaussian was $50 \mu \mathrm{m}$ in width with a $10 \mu \mathrm{m}$ SD. The smoothed data were then plotted as a surface heat plot.

To analyze how the bat's adaptive behaviors were tied to the timing of sensory responses (i.e., echo responses), and the lead time of vocal premotor activity, we first measured the pulse interval (PI) of all sonar vocalizations. The PI is defined as the time from the onset of one vocalization to the onset of the next vocalization. The entire range of vocalization intervals across bats approximately fell into three categories, short PIs of $<25 \mathrm{~ms}$, middle PIs of 30-60 ms, and long PIs of 75-250 ms.

We next calculated the latencies of auditory responses to echoes and vocal premotor lead times to sonar vocal onset. The time of echo arrival was calculated by first determining the target distance at the time of each 
sonar vocal onset, multiplying the target distance by 2 (the sonar signal travels from the bat to the target, and then back to the bat from the target), and calculating when the echo arrived at the bat, assuming a speed of sound in air of $344 \mathrm{~m} / \mathrm{s}$. The latency of auditory responses was then defined as the time from echo arrival to the first spike. This latency was calculated for all sensory neurons that were categorized through the methods described above. The lead time of vocal premotor activity was the time interval from sonar vocal onset to the first spike backwards in time (premotor spikes occur before sonar vocalizations). These lead times were calculated for all vocal premotor neurons that were categorized as described previously. We then sorted all lead times by the PI of the sonar vocalizations. We only included activity from neurons with at least 50 vocalizations in each of the short, middle, and long PI categories. Using a two-tailed test, we then tested whether the average sensory latencies and vocal premotor lead times were significantly different across short, middle, and long PI vocalizations.

\section{Results}

\section{Behavior and $\mathrm{SC}$ recordings}

Four big brown bats (E. fuscus) were trained under low-level, long-wavelength lighting to track a moving prey item from a stationary position by echolocation (see Fig. $1 A$ for the experiment setup). A 16-channel silicon probe mounted on a microdrive was then used to record chronically from the SC while the bats performed this target-tracking task. This resulted in recordings at 56 different sites in the four bats, totaling 526 neurons at recording depths ranging from 100-1200 $\mu \mathrm{m}$ (Covey et al., 1987; Wohlgemuth and Moss, 2016).

Echolocation is an active sensing system that permits discrete and selective sampling of acoustic information from the environment (Griffin, 1958; Ulanovsky and Moss, 2008; Moss and Surlykke, 2010). Therefore, we analyzed changes in SC activity with respect to the sonar vocal behavior of the bat. Among the 526 neurons we studied, 242 showed a significant increase in activity before and/or after the onset of the bat's sonar vocalizations (see Materials and Methods for selection criteria) and the other 284 neurons showed no significant change in activity around sonar vocal onset or echo arrival.

\section{Functional classification of $\mathrm{SC}$ neuron activity}

Neurons with sensory-related activity in the bat SC show an increase in activity related to sonar echo arrival, and responses therefore occur after the bat vocalizes when echoes return to the ears. Two example neurons exhibiting sensory (auditory) evoked activity are shown in Figure 2A. The top two panels of Figure $2 \mathrm{~A}$ display a raster and average firing rate plot of vocal aligned activity for a single neuron. In this example neuron, an increase in activity occurs at $\sim 18 \mathrm{~ms}$ after the onset of the sonar vocalization, when sonar echoes are returning to the bat. A similar response property is presented for a second example auditory neuron in the bottom two panels of Figure $2 A$, where there is a peak in activity $\sim 22 \mathrm{~ms}$ after sonar vocal onset at the time of echo arrival.

Vocal premotor signals in the bat SC are implicated in the production of sonar vocalizations and thus occur before vocal onset. Two example neurons demonstrating vocal premotor activity are shown in Figure 2B. In the top two panels (raster and firing rate plot), a vocal premotor neuron shows a burst of activity $\sim 20 \mathrm{~ms}$ before sonar vocal onset is shown. The bottom two panels of Figure $2 B$ display a vocal premotor neuron with a shorter vocal premotor lead time $(\sim 10 \mathrm{~ms})$.

The third category of SC neurons are the sensorimotor neurons - those displaying both sensory and vocal premotor activity. Two example sensorimotor neurons are presented in Figure 2C (top and bottom), each showing a burst of activity before and after sonar vocal onset. In total, 79 neurons were sensory and responded to sonar echoes, 83 neurons fired a vocal premotor burst before sonar vocalizations, and 80 neurons showed both sensory and vocal premotor activity and were therefore classified as sensorimotor. As is shown in Figure 2, sensory activity in the SC was broadly responsive to returning echoes and premotor neurons generally active before sonar vocalizations, in agreement with the broadly tuned SC neurons found in past work in visual mammals (McIlwain and Buser, 1968).

\section{Functional changes in SC activity across the dorsal-ventral axis}

Our recording technique allowed us to collect single neuron activity across the laminae of the SC throughout the course of the experiment. In doing so, we reconstructed the locations of sensory, sensorimotor, and motor neurons along the dorsal-ventral axis of the bat SC. Shown in Figure 3 is the distribution of recording depths for each category of neuron (sensory in blue, premotor in green, and sensorimotor in red). We found that, in general, sensory neurons are located at the most dorsal positions of the bat SC, whereas sensorimotor and motor neurons are found at the deepest locations (all pairwise comparisons of mean depths are significantly different; see details in Fig. 3 legend). However, we also identified auditory and vocal premotor neurons throughout the dorsal-ventral axis (Fig. 3, sensory neurons in blue, vocal premotor neurons in green). Sensorimotor neurons also span a large range of recording depths across the dorsal-ventral extent of the SC (Fig. 3, sensorimotor neurons in red).

To analyze more precisely the distribution of sensorimotor activity across the dorsal-ventral extent of the SC, we prepared histological sections of the bat brain to determine where along the dorsal-ventral axis the recordings were collected. Shown in Figure $3 B$ are three serial coronal sections from the SC of Bat A. Indicated in red are the locations of the lesions from the silicon probe tract and in black are the boundaries of the SC. We attempted to identify laminar subdivisions by referring to previous histological reconstructions in the bat and other species (Covey et al., 1987; May, 2006; Big Brown Bat Stereotaxis Brain Atlas, courtesy of E. Covey, University of Washington). From this histological reconstruction, we suggest that recordings made at depths $<300 \mu \mathrm{m}$ were in the stratum griseum superficiale (SGS) layers of the SC; recordings between 300 and $800 \mu \mathrm{m}$ were in the stratum griseum intermediale (SGI) layers; and recordings made at locations $>800 \mu \mathrm{m}$ were either in the stratum album intermediale (SAI) or stratum griseum profundum (SGP). We would like to note that comparative functional homologies of neuroanatomical divisions are not straightforward (Butler and Hodos, 2005) and our use of the nomenclature SGS, SGI, and SGP is intended to aid readers who are familiar with SC studies of visually dominant mammals.

Because our findings show that neurons with sensory and/or vocal premotor activity are distributed across layers in the in the bat SC, we analyzed neural activity carefully along a dorsal-ventral recording column within an experiment. An example of this analysis is shown in Figure 4, which displays recordings from one specific channel: channel 3 of the 16-channel silicon probe tracked through different recording depths. This analysis first involved identifying neural activity tied to the bat's echolocation behaviors. As in previous analyses and again shown in Figure $4 A$, we extracted windows of SC activity aligned to the onsets of the bat's sonar vocalizations and created raster plots (Fig. $4 A$, left) and firing rate plots (Fig. $4 A$, middle) of neural activity aligned to sonar vocal onset. The vocal-aligned mean firing rate $(50 \mathrm{~ms}$ 

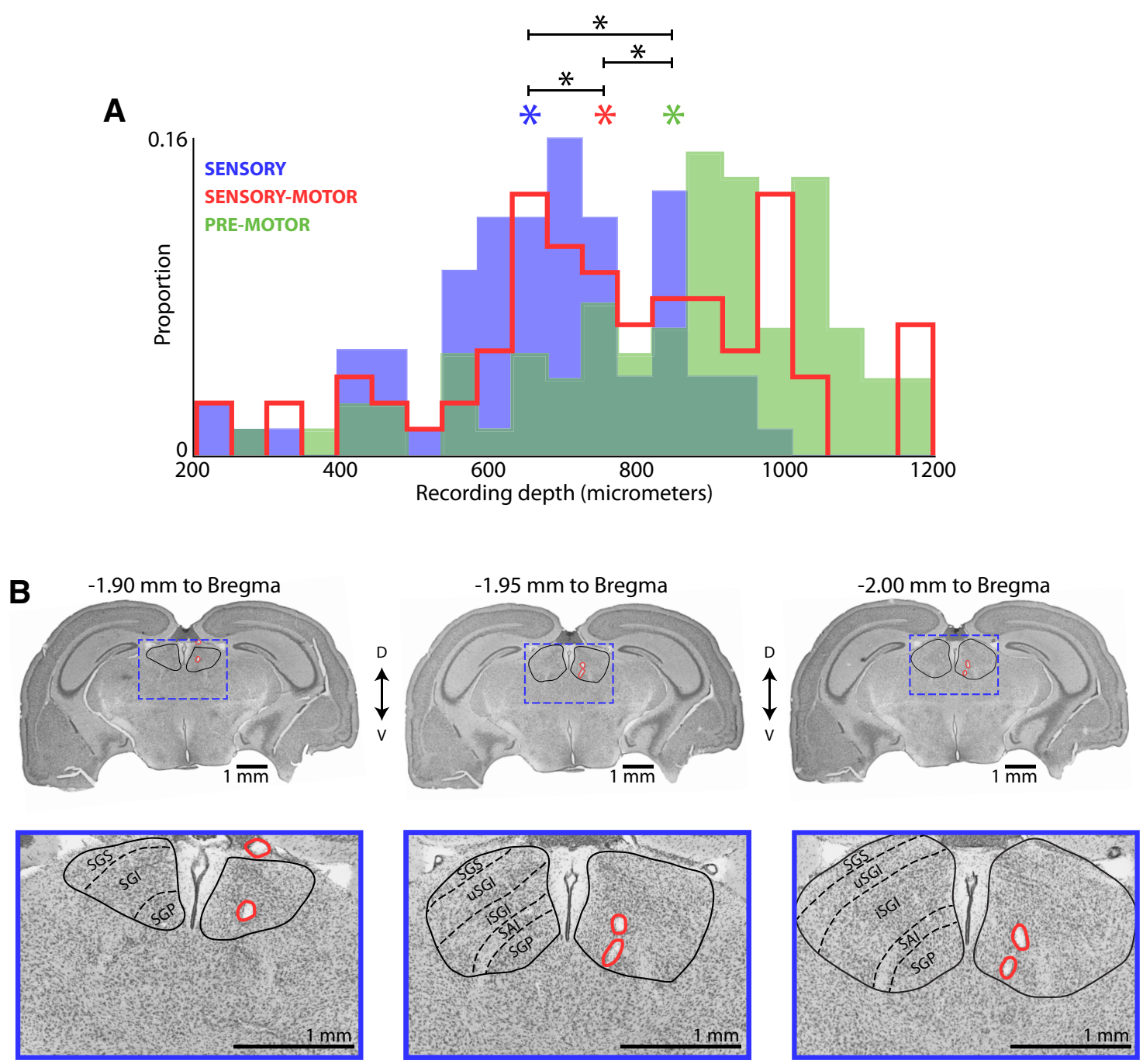

Figure 3. SC activity across the dorsal-ventral axis. A, Histogram of sampled recording depths in the SC with sensory (blue, $n=79$ ), sensorimotor (red, $n=80)$, or vocal premotor (green, $n=$ 83) neurons. Asterisks indicate mean depth for each functional class of neuron, sensory (blue), sensorimotor (red), premotor (green). Across all pairwise comparisons, the mean depths were significantly different (two-tailed t test, sensory vs sensorimotor, $p=5.2 \mathrm{e}^{-5}, \mathrm{df}=157$; sensorimotor vs motor, $p=2.7 \mathrm{e}^{-3}$, $\mathrm{df}=161$; sensory vs motor, $p=1.7 \mathrm{e}^{-10}$, $\mathrm{df}=160$ ). $\boldsymbol{B}$, Histological reconstruction of silicon probe tract. Left to right, Serial coronal sections arranged from rostral to caudal; the distance to bregma is indicated above each section. Lesions from silicon probe are indicated in red for each section, SC boundaries are shown with black lines, and the expanded portion of each coronal section on the bottom row are indicated in blue boxes on top row. Individual layers of the SC are also indicated in the expanded view of each coronal section on the bottom row. Identification of layers was performed by making comparisons with previous histological reconstructions in bats and other species (Covey et al., 1987; May, 2006; and Big Brown Bat Stereotaxis Brain Atlas, courtesy of E. Covey, University of Washington).

before sonar vocal onset and $50 \mathrm{~ms}$ after sonar vocal onset) was then converted into a heat plot for each isolated neuron (Fig. $4 \mathrm{~A}$, right, yellow is maximum rate, blue is minimum rate, white line is vocal onset). Shown in Figure $4 A$ is the spiking activity of one neuron on one recording channel (channel 3). As the silicon probe was advanced to a new location at the conclusion of each recording session, many different single neurons were isolated on channel 3 over days (Fig. 4B). The vocal-aligned activity patterns of all neurons recorded on channel 3 are plotted with respect to their recording depth in Figure $4 B$ (left, diagram of channel 3 through depths of the SC; middle, recording depths; right, vocalaligned activity heat plot; the example neuron in Fig. $4 A$ is identified with an asterisk). By displaying sonar vocal-aligned neural activity in this way, patterns of activity throughout the dorsalventral axis are visible. In the example shown in Figure 4, SC activity from channel 3 at all depths was mostly auditory, showing an increase in spiking activity in response to the returning target echo (Fig. $4 B$, right, increase in activity after white line indicating vocal onset), with a few sites showing vocal premotor activity before vocal onset along this columnar penetration throughout the SC. Note that there are also changes in the timing of neural activity with respect to sonar vocal onset across SC recording depths, with sharper temporal responses at intermediate sites.

Because the silicon probe used in our experiments has a consistent geometry (Fig. 4B, left, $100 \mu \mathrm{m}$ spacing between individual sites on a shank and $100 \mu \mathrm{m}$ spacing between shanks), it is possible to construct a more comprehensive overview of SC activity by analyzing activity across the channels of a single shank at different recording depths. Shown in Figure 5 are two different reconstructions of all SC neurons recorded on single shanks of the silicon probe during separate experiments. Figure $5 A$ displays all recorded SC neurons recorded on shank 1 from Bat A that have an increase in activity tied to sonar vocal onset (see Materials and Methods for the statistical criteria used). In this single shank penetration, SC activity is mostly auditory in dorsal locations (Fig. $5 \mathrm{~A}$, right, increase in activity after sonar vocal onset at more superficial recording sites), whereas neurons at ventral locations 
A

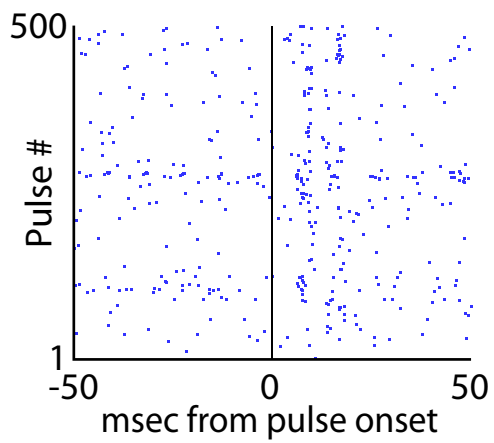

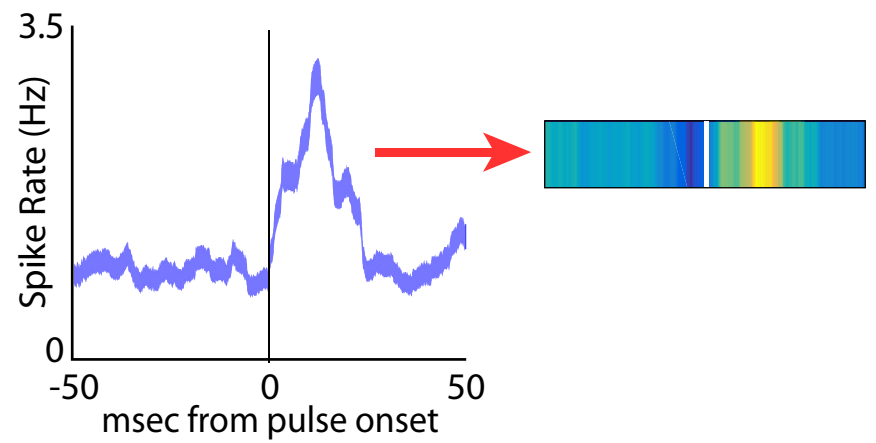

B $1000^{\text {Depth }(\mu \mathrm{m})}$
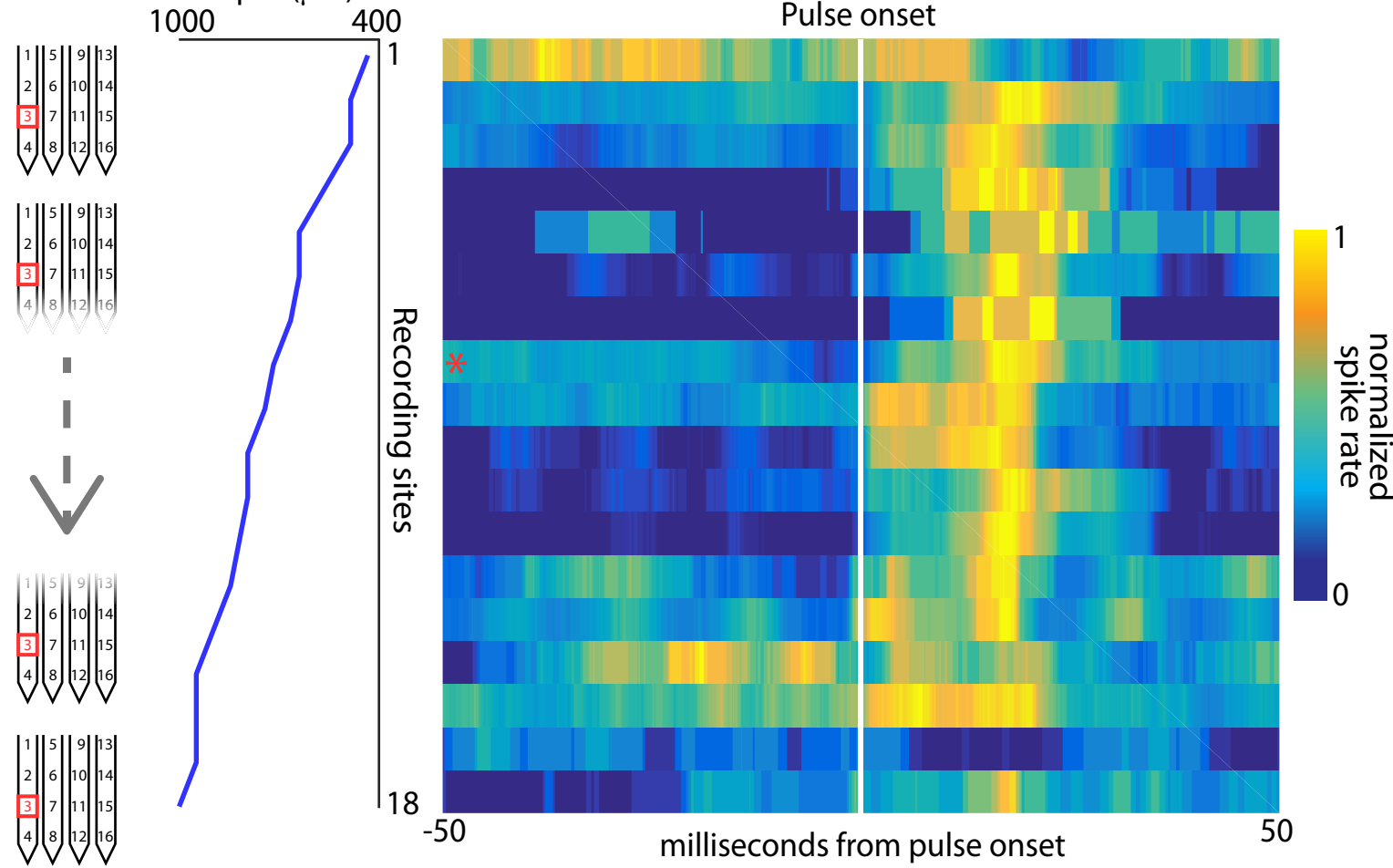

Figure 4. SC activity throughout recording depths for one channel (channel3) of the silicon probe. $\boldsymbol{A}$, Methodology of converting a spike raster into a heat plot for further analysis. Left, Spike raster for an $\mathrm{SC}$ neuron with activity after sonar vocal onset for 500 different vocalizations. Middle, Conversion of the spike raster into a firing rate plot displaying the average firing rate of the neuron with respect to the onset of the vocalization (zero time-point). The average firing rate in a $100 \mathrm{~ms}$ window aligned at vocal onset is then mapped onto a color spectrum from blue to yellow, with yellow representing the peak firing rate for that neuron (right, white line indicates pulse onset). B, Reconstruction of time-aligned SC activity throughout recording depths for channel 3 on the silicon probe (left column). This channel recorded different neurons at 18 locations across $600 \mu \mathrm{m}$ of layers in the SC (middle column). Right, Average activity of each neuron recorded arranged by depth and color coded as in $\boldsymbol{A}$ with yellow representing the peak firing rate and blue the minimum firing rate. Vocal onset is indicated with the white line; asterisk indicates neuron shown in $\boldsymbol{A}$.

are largely vocal premotor (Fig. $5 \mathrm{~A}$, right, shows an increase in activity before sonar vocal onset at deeper recording sites). However, this figure also shows that auditory responses are found in neurons at deeper locations in the SC and vocal premotor activity in neurons at more superficial locations, suggesting that the mapping of sensory and vocal premotor activity across the layers of the bat SC is more distributed than reported in previous studies of other mammalian species (Sparks and Hartwich-Young, 1989; May, 2006). This same trend is seen in the example shown in Figure $5 B$, which displays neural activity collected on shank 2 from Bat B tracked through different recording depths. Data recorded from shank 2 show more vocal premotor activity at dorsal sites than is seen in Figure $5 A$, but, similar to the example in Figure $5 A$, sensory and vocal premotor neurons are found throughout most recording depths.

The data shown in Figure 4 illustrate that vocal-aligned SC activity changes as a function of recording depth at one site as the probe was advanced, whereas Figure 5 shows changes in SC activity across dorsal-ventral sites on one probe shank; that is, four sites on one shank throughout recording depths. By combining data across all isolated neural activity at all recording depths, we constructed a summary of SC functional activity along the dorsal-ventral axis $(n=164$ unique recording sites at 41 different depths). Figure 6 reconstructs the mapping of sensory, vocal premotor, and sensorimotor activity through all dorsal-ventral SC recording sites by combining data across all silicon probe channels over the course of experiments in four animals. To construct this surface plot, spiking probability for each SC neuron aligned to sonar vocal onset was arranged according to recording depth and then convolved with a 2D Gaussian. The height of the peaks in the surface plot represents the probability of spiking at any given depth location in the SC with respect to sonar vocal onset (indicated with a white line). As in Figures 4 and 5, auditory 
activity occurs after sonar vocal onset (indicated in time with a blue rear wall of the figure) and vocal premotor activity precedes sonar vocalizations (indicated in time with a green rear wall in the figure). There is a general trend of sensory evoked activity at dorsal and intermediate locations and vocal premotor activity in ventral layers. This is illustrated by yellow peaks in the auditory region of the surface plot at shallow depths and yellow peaks in the vocal premotor region at deeper locations. Interestingly and importantly, auditory evoked activity appears at ventral locations, as indicated by the increased surface plot elevation after sonar vocal onset, as well as vocal premotor activity at more dorsal recording sites, as indicated by the increased surface plot elevation before sonar vocal onset at more superficial recording locations. These analyses show that there is a comingling of sensory, sensorimotor, and premotor signals across the dorsal-ventral extent of the bat SC. The local clusters of sensory, sensorimotor, and premotor neurons within laminae of the bat SC suggest a functional organization to support signaling between different classes of neurons for sensory-guided orientation.

\section{Dynamic changes in sensory and motor activity with adaptive behaviors}

For the bat, sensorimotor integration must be rapid to keep pace with the millisecond precision of echo processing and distancedependent adjustments in call timing. We hypothesize that, when sensorimotor processing demands are high, that is, when sonar calls and echoes occur in rapid succession, the activity of sensory and premotor neurons in the SC is modulated to accommodate processing demands of rapid sensory and motor events. We therefore investigated whether changes in the rate of the bat's vocal production alter the timing of sensory and vocal premotor neuron activity. As illustrated in Figure 1, the bat decreases PI (the time between the onset of one pulse to the onset of the next pulse) as the target approaches. Shown in Figure $7 A$ is the PI distribution of calls produced by the bats in the current study. This distribution is trimodal, so we categorized vocalization intervals into short PIs ( $<25 \mathrm{~ms})$, middle PIs (30-60 ms), and long PIs (75-250 ms) and examined changes in sensory and vocal premotor activity in single neurons across these three PI categories. For the sensory neurons shown in Figure 7B, there was a significant decrease in the latency between echo arrival and spike timing when bats produced calls in the shortest PI category (i.e., $<25 \mathrm{~ms}$ ), compared with middle and long PI categories. Figure $7 B$, left and right, show distributions of spike latencies
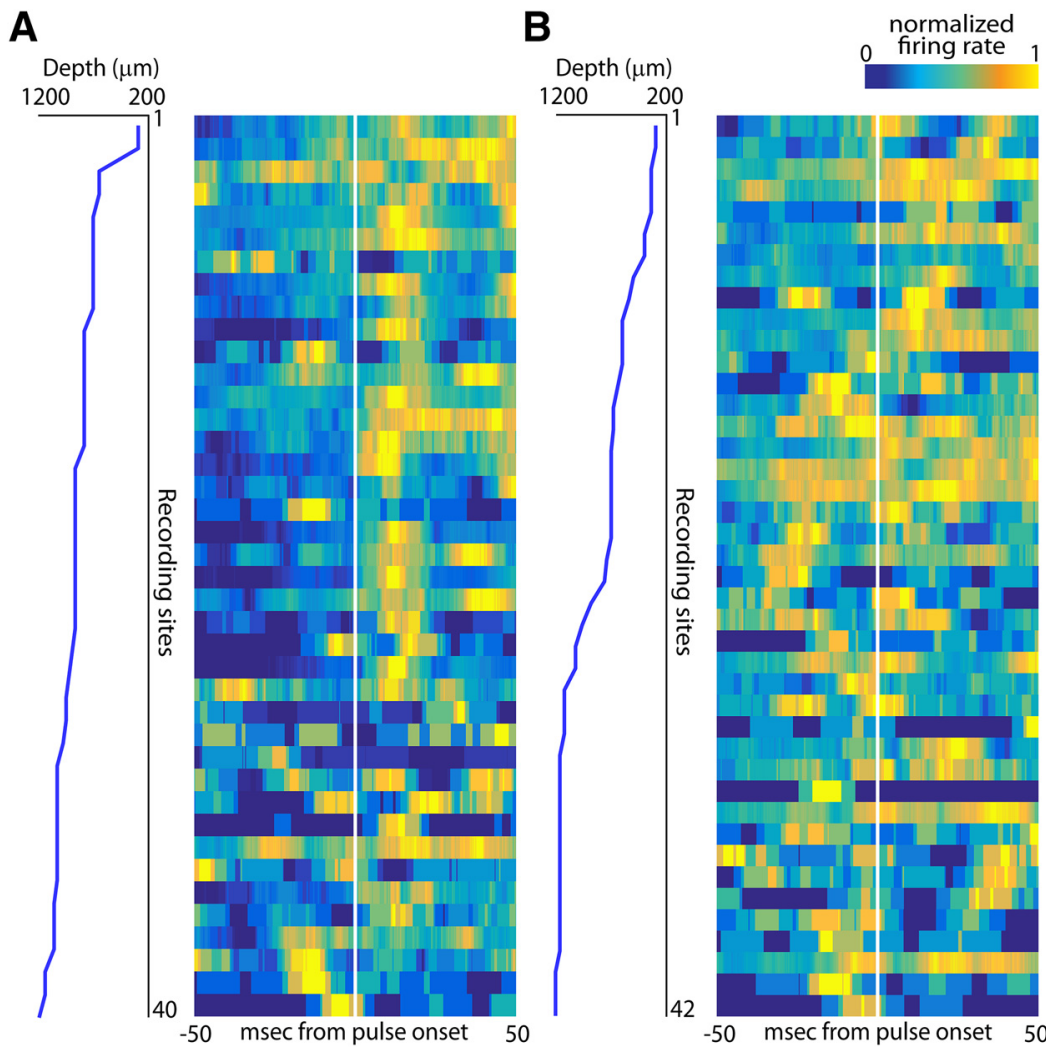

Figure 5. SC activity throughout recording depths for one shank of the silicon probe for two different bats. $\boldsymbol{A}$, Left, Recording depths for each site shown. Right, Heat map of vocal-aligned SC activity across all recording depths for one shank of the silicon probe (shank 1, Bat A). B, Left, Recording depths for each site shown. Right, Heat map of vocal-aligned SC activity across all recording depths for one shank of the silicon probe (shank 2, Bat B).

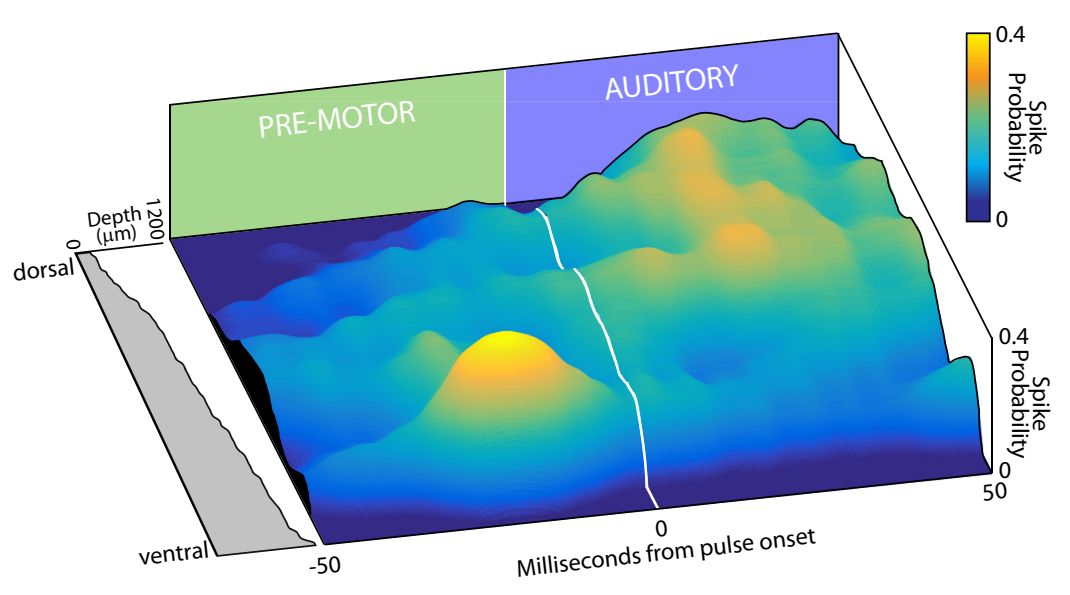

Figure 6. Sensory, sensorimotor, and vocal premotor mapping to recording depth. Shown is a reconstruction of 242 different neurons recorded across four bats, with spike probability in relation to sonar vocal onset arranged as a function of recording depth (left plot). Sonar vocal onset is indicated with the white line, with vocal premotor activity occurring before onset and auditory evoked activity after onset. Spiking probability is represented both as a color scale (blue to yellow) and as the height of the surface plot. In this plot, sensory evoked activity is more likely in dorsal layers and motor activity is more likely in ventral layers, but both sensory and motor activity can be found throughout the recording depths (indicated by elevations greater than zero in the surface plot).

with respect to echo arrival for two example sensory neurons; short PI shown in blue, middle PI in gray, and long PI in black. There is a significant decrease in spike latency for short PI vocalizations ( $p=0.001$ for left example, $p=0.002$ for right example, permutation test).

We extended this analysis to the entire population of neurons studied and tested whether auditory neurons show changes in 

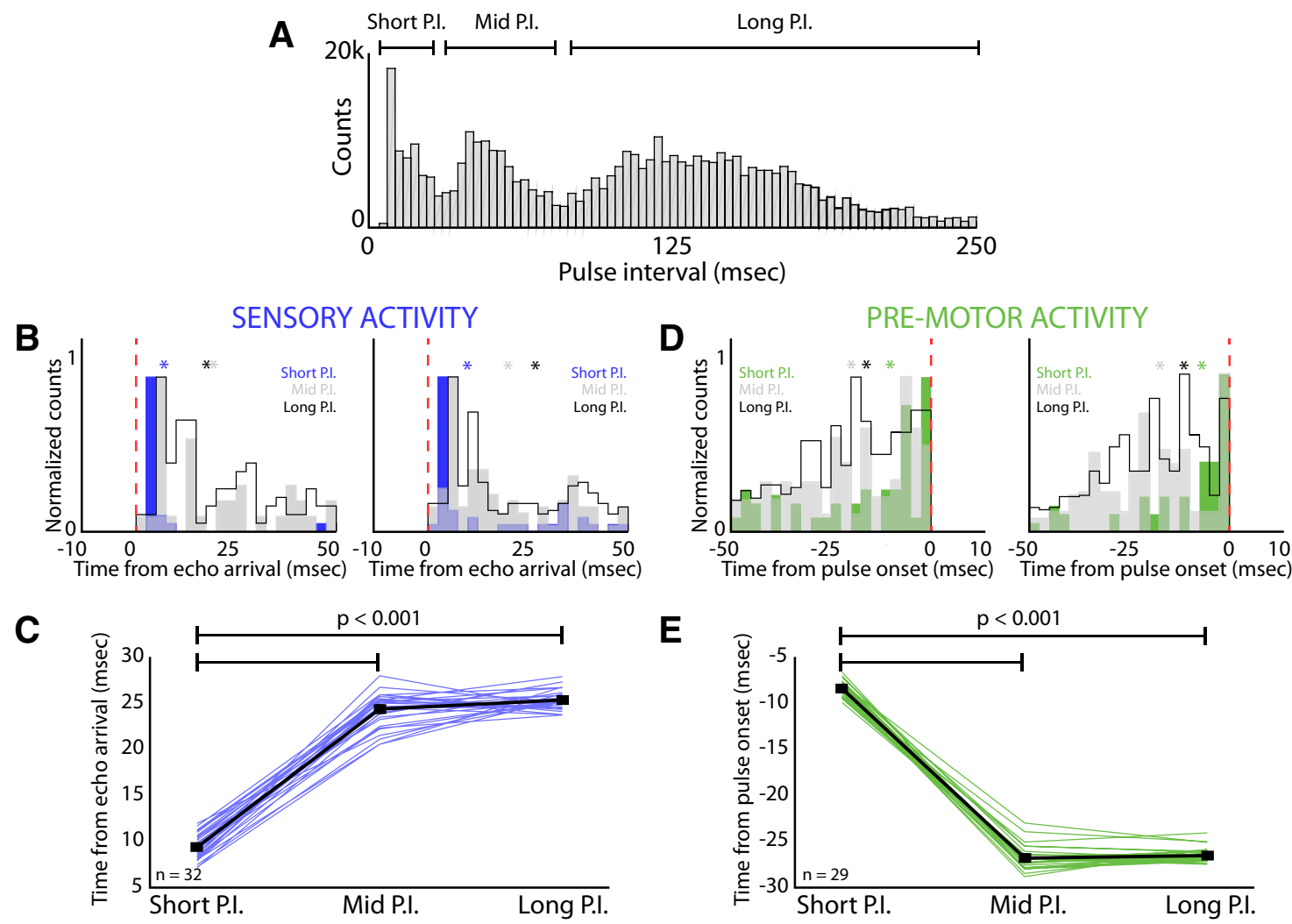

Figure 7. Effects of vocal motor production upon sensory responses. $A$, Distribution of Pls while bats tracked moving targets. There was a trimodal PI distribution, resulting in three different categories of PI: short Pls of $<25 \mathrm{~ms}$, middle Pls of $30-60 \mathrm{~ms}$, and long Pls of $75-250 \mathrm{~ms}$. $\boldsymbol{B}$, Latency from echo arrival to spike time for two sensory neurons (left and right) broken down by the PI of the ongoing vocalizations. For these two example sensory neurons, the latency from echo arrival to spike time is significantly shorter for the smallest PI category (short Pl in blue, $p=0.001$ for left example, $p=0.002$ for right example, permutation test for both comparisons). C, Change in latency from echo arrival to spike time across the three PI categories for sensory neurons ( $n=32$ neurons, minimum of 50 vocalizations in each PI category; asterisks denote mean values, colors as described). There is a significant decrease in the spike latency for echoes returned from short PI vocalizations compared with the middle and long PI vocalizations ( $p=0.0002$ for both comparisons, two-tailed $t$ test). $\boldsymbol{D}$, Lead time from spike time to pulse onset for two motor neurons (left and right). For both example motor neurons, the lead time from spike time to pulse onset is significantly shorter when the bat is producing vocalizations at the shortest PI (short PI in green, $p=0.001$ for left example, $p=0.02$ for right example, permutation test for both comparisons; asterisks denote mean values, colors as described). $\boldsymbol{E}$, Change in lead time from spike time to pulse onset across the three PI categories for motor neurons ( $n=29$ neurons, minimum of 50 vocalizations in each PI category). There is a significant decrease in spike lead time to pulse onset for short PI vocalizations compared with the middle and long PI vocalizations ( $p=0.0005$ for both comparisons, two-tailed $t$ test).

echo-evoked spike latencies across the three PI categories in which at least 50 vocalizations were produced in each PI category ( $n=32$ neurons). Across sensory neurons, we found a significant decrease in latency from echo arrival time to spike time for echoes returned after short PI vocalizations (Fig. $7 C, p=0.0002$, twotailed $t$ test). We performed a similar analysis for vocal premotor neurons and shown in Figure $7 D$ are the lead times from spike to pulse onset for two example vocal premotor neurons. Similar to sensory neurons, vocal premotor neurons showed a significant decrease in spike lead time of single neurons to pulse onset for short PI vocalizations. Figure $7 D$, left and right, show distributions of spike lead times with respect to pulse onset for two example vocal premotor neurons (short PI shown in green, middle PI in gray, and long PI in black; significant decrease in spike latencies for short PI vocalizations, $p=0.001$ for left example neuron, $p=0.02$ right example, permutation test). Across all vocal premotor neurons recorded, there was a significant decrease in lead time from spike to pulse onset for the vocalizations produced at short PIs (Fig. 7E, $p=0.0005$, two-tailed $t$ test, $n=$ 29 neurons). These results demonstrate that the timing of both sensory and vocal premotor activity is influenced by the rate at which bats produce echolocation calls and process information carried by echo returns.

\section{Discussion}

Sensorimotor processing is integral to a wide range of natural behaviors,yet research to date has emphasized the neural underpinnings of simplified visuomotor behaviors under controlled conditions (Sparks and Hartwich-Young, 1989; Gandhi and Katnani, 2011; Krauzlis et al., 2013). To extend this line of investigation to dynamic audiomotor integration in adaptive orienting behaviors, we characterized neural activity in the midbrain SC of echolocating bats engaged in a natural target-tracking task. We hypothesized that the SC would exhibit integrated laminar activity of sensory, sensorimotor, and vocal premotor neurons to support rapid audiomotor integration.

Although the functional organization of the SC is broadly conserved across mammals, there are differences in the number and size of layers, which are influenced by the dominant sensory modality used by an animal for spatial orientation (May, 2006). The upper layer in primates, the SGS is devoted to visual processing (May, 2006), reflecting this animal's reliance on visual orienting. The SGS is further divided into upper and lower sublaminae (i.e. upper stratum griseum superficiale and lower stratum griseum superficiale, or uSGS and ISGS, respectively) in the monkey and into three divisions in the cat, with a layer below the uSGS 
and ISGS, stratum opticum containing mostly fibers originating from the retina (May, 2006). In this study, we refer to the most dorsal region of the bat SC as the SGS based on anatomical location, but recognize that this nomenclature deviates from the canonical functional characterization of superficial layer neurons as visual. Past work in bats shows species differences in visual input to superficial layers. In the omnivorous pale spear-nosed bat, Phyllostomus discoler, neurons in the superficial SC responded to visual stimulation, were topographically organized, and in register with an auditory space map in deeper layers (Hoffmann et al., 2016). A study of the insectivorous bat Pteronotus parnellii revealed a very sparse retinal input layer and, indeed, it may be that intermediate layers of the bat SC invade the most superficial regions in species that rely primarily on hearing to orient themselves (Covey et al., 1987). Consistent with this view are neurophysiological recordings from the SC of insectivorous echolocating bats, which show robust auditory activity in the most dorsal layers (Jen et al., 1984; Poussin and Schlegel, 1984; Shimozawa et al., 1984; Wong, 1984; Valentine and Moss, 1997). However, neuroanatomical comparisons across species warrant caution (Butler and Hodos, 2005).

The intermediate layers of the SC or SGI are unimodal, multimodal, and sensorimotor in primate, cat, and rodent (May, 2006). The SGI is further divided into two or three subdivisions, depending upon the convention. The upper SGI (uSGI) contains cell bodies, whereas the lower division(s) contains fewer cell bodies and fibers of passage running along the rostral-caudal dimension. Sensory representations in SGI include visual, auditory, and somatosensory neurons (Meredith and Stein, 1986; May, 2006) and visual SGI neurons show both sensory and premotor activity (Mays and Sparks, 1980), with some variations across species. In addition, neurons in the SGI display facilitated responses to multimodal stimuli (Meredith and Stein, 1986), suggesting a potential interaction between sensory neurons in these laminae of the SC. Our data show auditory, audiomotor, and vocal premotor neurons in intermediate layers of the bat SC, implying that interactions may occur among neurons of different functional classes as the bat engages in adaptive spatial orienting behaviors.

Below the SGI is the SAI, which contains fibers of passage and is considered to be the most ventral portion of the intermediate zone. The adjacent ventral layer contains more cell bodies and is termed SGP layer (May, 2006). Recordings from the SGP in the primate SC show neurons with premotor fields for saccadic eye movements (Sparks, 1986; Sparks and Hartwich-Young, 1989; Munoz et al., 1991b). Previous work also reports visual, auditory, somatosensory, and multisensory neurons in ventral SC across species (Wise and Irvine, 1983, 1985; Jen et al., 1984; Shimozawa et al., 1984; Wallace et al., 1996; Hoffmann et al., 2016). At ventral SC locations in our study, vocal premotor neurons were active before sonar vocalizations, consistent with earlier studies of the bat (Sinha and Moss, 2007).

The majority of our recordings were taken at depths $>400$ $\mu \mathrm{m}$, which we identify as intermediate and deep layers. At intermediate depths, in the SGI layers, we found a mix of sensory, sensorimotor, and vocal premotor neurons, which is in agreement with previous reports in other animals (May, 2006). The most ventral recording sites, which may be homologous to the SAI and SGP layers, contained a preponderance of sensorimotor and vocal premotor neurons. The largest increase in vocal premotor activity was at depths $>800 \mu \mathrm{m}$ (Fig. 7), within the traditionally defined motor layers of the SC (Ma et al., 1990; May, 2006).

Previous multiunit recordings from the SC of big brown bats revealed two bursts of activity preceding each sonar vocalization: one burst at short lead time and locked to vocal onset and a second burst at a longer and variable lead time (Sinha and Moss, 2007). These prior results raise the question of whether activity before vocalizations in the bat SC influences sonar call parameters or serves as efference motor signals. Sinha and Moss (2007) propose that the long lead time vocal premotor activity is implicated in shaping sonar call features, whereas the precisely timed short-lead premotor burst marks the time of sonar emission for echo delay measurement. In our single unit recordings, we mostly identified increased activity before sonar vocalizations at variable lead times (Fig. 7). We therefore cannot conclude that the single unit vocal premotor activity in our study represents an efference signal of call onset time.

What is important, and currently unknown, is the connectivity between sensory and premotor neurons in the bat SC. Prior anatomical work in visual mammals demonstrated that intralaminar connectivity patterns differ across SC layers (Isa, 2002; May, 2006; Isa and Hall, 2009; Vokoun et al., 2011; Bayguinov et al., 2015). Superficial layers have larger inhibitory networks that enable surround suppression (Mize, 1988; Behan and Appell, 1992). More ventral layers, however, show a mixture of inhibitory and excitatory connections within layers (McIlwain, 1982; Munoz and Istvan, 1998). Intralaminar organization may differ in the bat, but we hypothesize that neurons in the same layers are also functionally connected and that the colocalization of sensory and premotor neurons within layers facilitates local interactions. Testing this hypothesis in bats and other animals would contribute to broader comparative analyses that would help to differentiate between species-specific specializations and general mechanisms.

Ultimately, an animal must integrate sensory information from the environment to select appropriate actions. Prior work on the SC demonstrates interactions within the same subregions, that alter activity in a variety of ways (Meredith and Stein, 1986; Wallace et al., 1996; Stein, 1998). For instance, studies of the intermediate layers of the SC have shown that a neuron can be either inhibited or facilitated by multimodal stimulation depending on the timing of sensory inputs through each channel (Meredith and Stein, 1983; King and Palmer, 1985). This suggests a mechanism by which streams of information can activate SC neurons differentially. In addition, auditory neurons in the primate SC show shifts in spatial tuning with eye position (Jay and Sparks, 1984; Groh et al., 2001), revealing multimodal-sensorimotor interactions. We posit that interactions between pools of local neurons with different functional properties in the bat SC enable the dynamic audiomotor integration intrinsic to echolocation.

How might comingling of sensory and premotor neurons within laminae enable sensorimotor processing for natural behaviors? To provide a possible answer, we analyzed natural variations in echolocation call parameters with respect to changes in SC sensory and vocal premotor signaling. As a bat tracks prey, vocal rate increases with decreasing target distance (Griffin, 1958). This adaptive vocal behavior increases echo sample rate and can therefore increase sensory resolution (Ulanovsky and Moss, 2008). We analyzed the activity of SC sensory and vocal premotor neurons with respect to changes in sonar temporal patterning and found significant changes in SC activity when the bat produced vocalizations at the highest rates (i.e., the shortest PIs). When the bat produced vocalizations at rates $>40$ calls/s, response latencies of sensory neurons and spike lead time to vocal onset of vocal premotor neurons were significantly shorter. These results show that both sensory and vocal premotor neurons change activity patterns when the bat increases its sonar sample rate before prey capture. 
There are several mechanisms that could be responsible for the shortened echo response latencies and vocal premotor lead times during high call rates. For example, sensory latencies could be reduced through mechanisms similar to forward suppression, as described previously in both the cortex (Beetz et al., 2016) and midbrain (Voytenko and Galazyuk, 2010; Tang et al., 2015) of bats. In this scheme, global inhibition shapes responses such that the brain responds only to a salient stimulus. In the inferior colliculus and auditory cortex of bats, forward suppression could sharpen the selectivity of auditory responses to the temporal features of natural echolocation stimuli (Sanderson and Simmons, 2002, 2005). In our data, forward suppression would allow for faster and more precise response times in auditory neurons.

In vocal premotor neurons, it is possible that another mechanism drives the decrease in premotor lead times with increasing call rate. Prior studies in the SC have demonstrated decreases in saccadic reaction times in primates by "priming" the system through subthreshold microstimulation (Carello and Krauzlis, 2004; Müller et al., 2005). Our results complement this finding, showing that a natural source of SC priming, high call rates and increased echo returns, shortens the lead time of vocal premotor neurons.

When bats produce echolocation calls at relatively high rates, the activity levels of both sensory and vocal premotor neurons often increase. This could provide a functional substrate for shortened spike latencies; i.e. increases in sensory activity can drive more global suppression and/or lateral inhibition leading to sharpened responses, while increases in baseline motor activity can act to prime the system for shorter lead time premotor signals. It is possible that both of these mechanisms are at play for sensory and motor neurons, but, importantly, our findings show that local pools of sensory and premotor neurons have the spatial proximity to communicate quickly and keep pace with sensorimotor processing demands. These findings lead us to propose that the functional organization of the bat SC supports local and rapid integration of behaviorally modulated sensory and premotor signals for acoustic orientation by sonar.

In conclusion, we have characterized neural activity throughout the dorsal-ventral axis of the SC in an echolocating bat engaged in a dynamic and natural target-tracking task. Our results revealed a distribution of sensory, sensorimotor, and premotor neurons within laminae, which leads us to hypothesize that local pools of sensory and premotor neurons interact to mediate adaptive sensorimotor behaviors. Furthermore, we discovered that adaptive echolocation behavior evokes changes in sensory and premotor signaling in the bat SC, which may arise through local loops of sensorimotor signaling. Future comparative studies of SC activity in other species engaged in natural and dynamic orienting tasks will provide important data to test this hypothesis.

\section{References}

Bayguinov PO, Ghitani N, Jackson MB, Basso MA (2015) A hard-wired priority map in the superior colliculus shaped by asymmetric inhibitory circuitry. J Neurophysiol 114:662-676. CrossRef Medline

Beetz MJ, Hechavarría JC, Kössl M (2016) Temporal tuning in the bat auditory cortex is sharper when studied with natural echolocation sequences. Sci Rep 6:29102. CrossRef Medline

Behan M, Appell PP (1992) Intrinsic circuitry in the cat superior colliculus: projections from the superficial layers. J Comp Neurol 315:230-243. CrossRef Medline

Berson DM, Stein JJ (1995) Retinotopic organization of the superior colliculus in relation to the retinal distribution of afferent ganglion cells. Vis Neurosci 12:671-686. CrossRef Medline

Brandão ML, Cardoso SH, Melo LL, Motta V, Coimbra NC (1994) Neural substrate of defensive behavior in the midbrain tectum. Neurosci Biobehav Rev 18:339-346. CrossRef Medline
Butler AB, Hodos W (2005) Comparative vertebrate neuroanatomy: evolution and adaptation. New York: Wiley Interscience.

Carello CD, Krauzlis RJ (2004) Manipulating intent: Evidence for a causal role of the superior colliculus in target selection. Neuron 43:575-583. CrossRef Medline

Comoli E, Das Neves Favaro P, Vautrelle N, Leriche M, Overton PG, Redgrave P (2012) Segregated anatomical input to sub-regions of the rodent superior colliculus associated with approach and defense. Front Neuroanat 6:9. CrossRef Medline

Covey E, Hall WC, Kobler JB (1987) Subcortical connections of the superior colliculus in the mustache bat, Pteronotus parnellii. J Comp Neurol 263: 179-197. CrossRef Medline

Cynader M, Berman N (1972) Receptive-field organization of monkey superior colliculus. J Neurophysiol 35:187-201. Medline

du Lac S, Knudsen EI (1990) Neural maps of head movement vector and speed in the optic tectum of the barn owl. J Neurophysiol 63:131-146. Medline

Fanselow MS (1994) Neural organization of the defensive behavior system responsible for fear. Psychon Bull Rev 1:429-438. CrossRef Medline

Furigo IC, de Oliveira WF, de Oliveira AR, Comoli E, Baldo MV, Mota-Ortiz SR, Canteras NS (2010) The role of the superior colliculus in predatory hunting. Neuroscience 165:1-15. CrossRef Medline

Gandhi NJ, Katnani HA (2011) Motor functions of the superior colliculus. Annu Rev Neurosci 34:205-231. CrossRef Medline

Goldberg ME, Wurtz RH (1972) Activity of superior colliculus in behaving monkey. I. Visual receptive fields of single neurons. J Neurophysiol 35: 542-559. Medline

Griffin D (1958) Listening in the dark: the acoustic orientation of bats and men. New Haven, CT: Yale University.

Grobstein P (1988) Between the retinotectal projection and directed movement: topography of a sensorimotor interface. Brain Behav Evol 31:3448. CrossRef Medline

Groh JM, Trause AS, Underhill AM, Clark KR, Inati S (2001) Eye position influences auditory responses in primate inferior colliculus. Neuron 29: 509-518. CrossRef Medline

Hartline PH, Kass L, Loop MS (1978) Merging of modalities in the optic tectum: infrared and visual integration in rattlesnakes. Science 199:12251229. CrossRef Medline

Hoffmann S, Vega-Zuniga T, Greiter W, Krabichler Q, Bley A, Matthes M, Zimmer C, Firzlaff U, Luksch H (2016) Congruent representation of visual and acoustic space in the superior colliculus of the echolocating bat Phyllostomus discolor. Eur J Neurosci 44:2685-2697. CrossRef Medline

Hope GM, Bhatnagar KP (1979) Electrical response of bat retina to spectral stimulation: comparison of four microchiropteran species. Experientia 35:1189-1191. CrossRef Medline

Isa $\mathrm{T}$ (2002) Intrinsic processing in the mammalian superior colliculus. Curr Opin Neurobiol 12:668-677. CrossRef Medline

Isa T, Hall WC (2009) Exploring the superior colliculus in vitro. J Neurophysiol 102:2581-2593. CrossRef Medline

Jay MF, Sparks DL (1984) Auditory receptive fields in primate superior colliculus shift with changes in eye position. Nature 309:345-347. CrossRef Medline

Jay MF, Sparks DL (1987) Sensorimotor integration in the primate superior colliculus. II. Coordinates of auditory signals. J Neurophysiol 57:35-55. Medline

Jen PH, Sun X, Kamada T, Zhang S, Shimozawa T (1984) Auditory response properties and spatial response areas of superior collicular neurons of the FM bat, Eptesicus fuscus. J Comp Physiol A Neuroethol Sens Neural Behav Physiol 154:407-413. CrossRef

Kavaliers M, Choleris E (2001) Antipredator responses and defensive behavior: ecological and ethological approaches for the neurosciences. Neurosci Biobehav Rev 25:577-586. CrossRef Medline

King AJ, Palmer AR (1985) Integration of visual and auditory information in bimodal neurones in the guinea-pig superior colliculus. Exp Brain Res 60:492-500. Medline

Knudsen EI (1982) Auditory and visual maps of space in the optic tectum of the owl. J Neurosci 2:1177-1194. Medline

Kothari NB, Wohlgemuth MJ, Hulgard K, Surlykke A, Moss CF (2014) Timing matters: sonar call groups facilitate target localization in bats. Front Physiol 5:168. CrossRef Medline

Krauzlis RJ, Lovejoy LP, Zénon A (2013) Superior colliculus and visual spatial attention. Annu Rev Neurosci 36:165-182. CrossRef Medline 
Lee J, Groh JM (2012) Auditory signals evolve from hybrid- to eye-centered coordinates in the primate superior colliculus. J Neurophysiol 108:227242. CrossRef Medline

Ma TP, Cheng HW, Czech JA, Rafols JA (1990) Intermediate and deep layers of the macaque superior colliculus: a Golgi study. J Comp Neurol 295:92-110. CrossRef Medline

Maior RS, Hori E, Uribe CE, Saletti PG, Ono T, Nishijo H, Tomaz C (2012) A role for the superior colliculus in the modulation of threat responsiveness in primates: toward the ontogenesis of the social brain. Rev Neurosci 23:697-706. CrossRef Medline

May PJ (2006) The mammalian superior colliculus: laminar structure and connections. Prog Brain Res 151:321-378. CrossRef Medline

Mays LE, Sparks DL (1980) Dissociation of visual and saccade-related responses in superior colliculus neurons. J Neurophysiol 43:207-232. Medline

McIlwain JT (1982) Lateral spread of neural excitation during microstimulation in intermediate gray layer of cat's superior colliculus. J Neurophysiol 47:167-178. Medline

McIlwain JT (1983) Representation of the visual streak in visuotopic maps of the cat's superior colliculus: influence of the mapping variable. Vision Res 23:507-516. CrossRef Medline

Mcllwain JT, Buser P (1968) Receptive fields of single cells in the cat's superior colliculus. Exp Brain Res 5:314-325. Medline

McIlwain JT (1991) Distributed spatial coding in the superior colliculus: a review. Vis Neurosci 6:3-13. CrossRef Medline

Meredith MA, Stein BE (1983) Interactions among converging sensory inputs in the superior colliculus. Science 221:389-391. CrossRef Medline

Meredith MA, Stein BE (1986) Visual, auditory, and somatosensory convergence on cells in superior colliculus results in multisensory integration. J Neurophysiol 56:640-662. Medline

Middlebrooks JC, Knudsen EI (1984) A neural code for auditory space in the cat's superior colliculus. J Neurosci 4:2621-2634. Medline

Mize RR (1988) Immunocytochemical localization of gamma-aminobutyric acid (GABA) in the cat superior colliculus. J Comp Neurol 276:169-187. CrossRef Medline

Moss CF, Surlykke A (2010) Probing the natural scene by echolocation in bats. Front Behav Neurosci 4: pii: 33. CrossRef Medline

Müller JR, Philiastides MG, Newsome WT (2005) Microstimulation of the superior colliculus focuses attention without moving the eyes. Proc Natl Acad Sci U S A 102:524-529 CrossRef Medline

Munoz DP, Istvan PJ (1998) Lateral inhibitory interactions in the intermediate layers of the monkey superior colliculus. J Neurophysiol 79:11931209. Medline

Munoz DP, Guitton D, Pélisson D (1991a) Control of orienting gaze shifts by the tectoreticulospinal system in the head-free cat. III. Spatiotemporal characteristics of phasic motor discharges. J Neurophysiol 66:1642-1666. Medline

Munoz DP, Pélisson D, Guitton D (1991b) Movement of neural activity on the superior colliculus motor map during gaze shifts. Science 251:13581360. CrossRef Medline

Peck CK (1990) Neuronal activity related to head and eye movements in cat superior colliculus. J Physiol 421:79-104. CrossRef Medline

Poussin C, Schlegel P (1984) Directional sensitivity of auditory neurons in the superior colliculus of the bat, Eptesicus fuscus, using free field sound stimulation. J Comp Physiol A Neuroethol Sens Neural Behav Physiol 154:253-261. CrossRef

Quiroga RQ, Nadasdy Z, Ben-Shaul Y (2004) Unsupervised spike detection and sorting with wavelets and superparamagnetic clustering. Neural computation 16:1661-1687. CrossRef Medline

Roucoux A, Crommelinck M (1976) Eye movements evoked by superior colliculus stimulation in the alert cat. Brain Res 106:349-363. CrossRef Medline

Sanderson MI, Simmons JA (2002) Selectivity for echo spectral interference and delay in the auditory cortex of the big brown bat Eptesicus fuscus. J Neurophysiol 87:2823-2834. Medline

Sanderson MI, Simmons JA (2005) Target representation of naturalistic echolocation sequences in single unit responses from the inferior colliculus of big brown bats. J Acoust Soc Am 118:3352-3361. CrossRef Medline

Schiller PH, Koerner F (1971) Discharge characteristics of single units in superior colliculus of the alert rhesus monkey. J Neurophysiol 34:920936. Medline
Shimozawa T, Sun X, Jen PH (1984) Auditory space representation in the superior colliculus of the big brown bat, Eptesicus fuscus. Brain Res 311: 289-296. CrossRef Medline

Sinha SR, Moss CF (2007) Vocal premotor activity in the superior colliculus. J Neurosci 27:98-110. CrossRef Medline

Sparks DL (1986) Translation of sensory signals into commands for control of saccadic eye movements: role of primate superior colliculus. Physiol Rev 66:118-171. Medline

Sparks DL, Hartwich-Young R (1989) The deep layers of the superior colliculus. Rev Oculomot Res 3:213-255. Medline

Stein BE (1998) Neural mechanisms for synthesizing sensory information and producing adaptive behaviors. Exp Brain Res 123:124-135. CrossRef Medline

Stuphorn V, Hoffmann KP, Miller LE (1999) Correlation of primate superior colliculus and reticular formation discharge with proximal limb muscle activity. J Neurophysiol 81:1978-1982. Medline

Stuphorn V, Bauswein E, Hoffmann KP (2000) Neurons in the primate superior colliculus coding for arm movements in gaze-related coordinates. J Neurophysiol 83:1283-1299. Medline

Tang J, Fu ZY, Wei CX, Chen QC (2015) Effect of echolocation behaviorrelated constant frequency-frequency modulation sound on the frequency tuning of inferior collicular neurons in Hipposideros armiger. J Comp Physiol A Neuroethol Sens Neural Behav Physiol 201:783-794. CrossRef Medline

Ulanovsky N, Moss CF (2008) What the bat's voice tells the bat's brain. Proc Natl Acad Sci U S A 105:8491-8498. CrossRef Medline

Valentine DE, Moss CF (1997) Spatially selective auditory responses in the superior colliculus of the echolocating bat. J Neurosci 17:1720-1733. Medline

Valentine DE, Sinha SR, Moss CF (2002) Orienting responses and vocalizations produced by microstimulation in the superior colliculus of the echolocating bat, Eptesicus fuscus. J Comp Physiol A Neuroethol Sens Neural Behav Physiol Neuroethol Sens Neural Behav Physiol 188:89-108. CrossRef

Vokoun CR, Jackson MB, Basso MA (2011) Circuit dynamics of the superior colliculus revealed by in vitro voltage imaging. Ann N Y Acad Sci 1233:41-47. CrossRef Medline

Voytenko SV, Galazyuk AV (2010) Suppression of spontaneous firing in inferior colliculus neurons during sound processing. Neuroscience 165: 1490-1500. CrossRef Medline

Wagner H, Kettler L, Orlowski J, Tellers P (2013) Neuroethology of prey capture in the barn owl (Tyto alba L.). J Physiol Paris 107:51-61. CrossRef Medline

Wallace MT, Wilkinson LK, Stein BE (1996) Representation and integration of multiple sensory inputs in primate superior colliculus. J Neurophysiol 76:1246-1266. Medline

Werner W, Dannenberg S, Hoffmann KP (1997) Arm-movement-related neurons in the primate superior colliculus and underlying reticular formation: comparison of neuronal activity with EMGs of muscles of the shoulder, arm and trunk during reaching. Exp Brain Res 115:191-205. CrossRef Medline

Wise LZ, Irvine DR (1983) Auditory response properties of neurons in deep layers of cat superior colliculus. J Neurophysiol 49:674-685. Medline

Wise LZ, Irvine DR (1985) Topographic organization of interaural intensity difference sensitivity in deep layers of cat superior colliculus: implications for auditory spatial representation. J Neurophysiol 54:185-211. Medline

Wohlgemuth MJ, Kothari NB, Moss CF (2016a) Action enhances acoustic cues for 3-D target localization by echolocating bats. PLoS Biol 14: e1002544. CrossRef Medline

Wohlgemuth MJ, Moss CF (2016) Midbrain auditory selectivity to natural sounds. Proc Natl Acad Sci U S A 113:2508-2513. CrossRef Medline

Wohlgemuth MJ, Luo J, Moss CF (2016b) Three-dimensional auditory localization in the echolocating bat. Curr Opin Neurobiol 41:78-86. CrossRef Medline

Wong D (1984) Spatial tuning of auditory neurons in the superior colliculus of the echolocating bat, Myotis lucifugus. Hear Res 16:261-270. CrossRef Medline

Wurtz RH, Goldberg ME (1971) Superior colliculus cell responses related to eye movements in awake monkeys. Science 171:82-84. CrossRef Medline 